\title{
A Multicriteria Evaluation Model to Optimally Place Grid-Connected Photovoltaic Power Plants
}

\author{
J. Arán-Carrión, A. F. Ramos-Ridao, F. Aznar-Dols, E. Alameda-Hernández and A. Espín-Estrella \\ Department of Civil Engineering \\ School of Civil Engineering, University of Granada \\ Campus Fuentenueva - 18071 Granada (Spain) \\ Phone number:+0034 958240463 , \\ e-mail: comercial@cimaconsultores.net,ramosr@ugr.es, faznar@ugr.es, ealameda@ugr.es, aespin@ugr.es
}

\begin{abstract}
The grid connected photovoltaic power plant location problem has shown to be really complex over the last few years. Engineers and scientists have shown deep interest in developing an efficient tool able to consider all distinct variables that enter into the problem.
\end{abstract}

This work designs a model that, using Geographic Information Systems and a Multicriteria Evaluation Methodology, has proven to be a very valuable tool for spatial analysis which is of great help when making decisions about the Optimal Location of grid connected photovoltaic power plants, considering in this decision both electrical and environmental factors.

\section{Key words}

Geographic information systems, multicriteria evaluation, photovoltaic power plant.

\section{Introduction}

The outstanding increase of ton of oil equivalent consumption to satisfy world energy demand, caused by the population grow and per-capita energy consumption increase, will impact on the fossil fuel prices. International efforts to promote renewable energy and energy efficiency are mandatory to reduce this tendency.

Photovoltaic technologies and others renewable energies are growing at a much faster pace than the rest of European economy. This fact and the dramatic increases of oil prices since 2005 have led to a political institution relaunch of renewable energy via measures to achieve their development, including and most importantly, economic incentives. Photovoltaics has been one of the technologies that attained better results due to existing incentives.
The main effect that the increase in projected and built grid connected photovoltaic power plants have had is to spot numerous optimal location errors regarding: output efficiency, law observing and costs reduction (both during construction and posterior maintenance).

\section{Model definition}

The chart shows all the steps required to build the proposed model.

This is a multicriteria evaluation system with one objective and several criteria. Firstly, as the chart indicates, the objective is determined, then the criteria and factors are established, both those of relative importance and those excluding. Defining an appropriate methodology to assign each criterion and factor weights has been the next step.

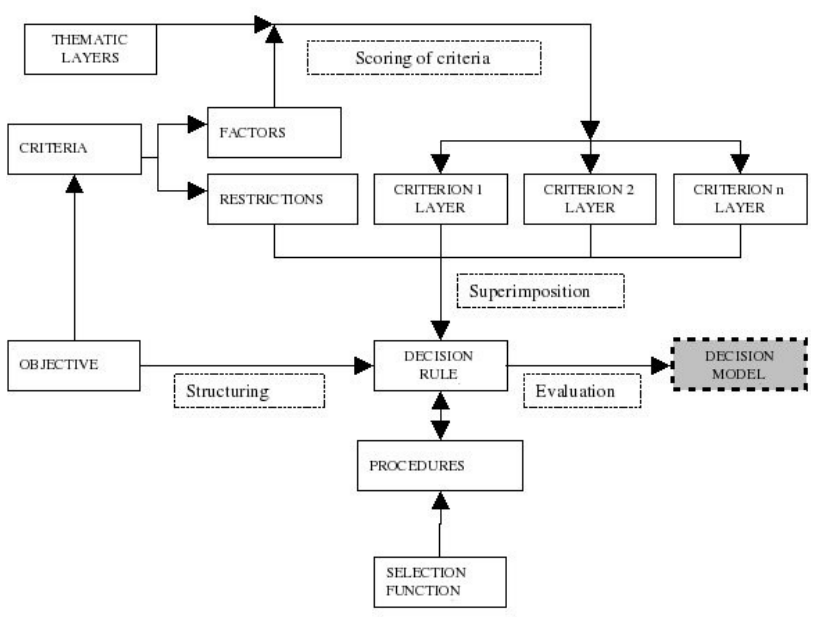

Chart: flow chart for model design 
Once the weights are established, they are introduced in a geographic information system (GIS), using ArcView 3.2 software with the Spatial Analyst extension that includes the Model Builder tool, through which the properly hierarchied layers can be obtained [1].

Using the Model Builder extension the relationship between different information layers falling on the same spot can be studied.

Thematic layers included in the model come from commercially available data bases. Other layers of both excluding and positive factors that have been developed for this work by the authors, falling in the Andalusian region, are the following:

1. Annual average daily temperatures.

2. Annual solar irradiance on horizontal surface.

3. Diffuse solar irradiance.

4. Annual sun hours equivalent (figure 1).

5. Power substations location.

6. Visual impact.

7. Slopes.

8. Orientation.

The next step was to group all these layers according to the different factors and to normalise them, by assigning a value within a 1 to 10 scale, being 1 the worst value and 10 the best.

These input topics, originally in vector form, have been converted to raster format (via Vector Conversion function), and later, in order to obtain discrete topics have gone through a reclassification process.

Finally, a Weighted Overlay process was applied to all the topics. With this, a combined output topic was created considering all the input topics falling in a certain geographic region.

The territory capacity (to install PV power plants) can be established from knowledge about the territory appropriateness and impact on it; that is, integrating these two elements we could propose different capacity levels for the special units that conform the territory under study from a certain use or activity.

Given that the territory capacity can be understood as the sum of all positive factors minus all negatives (or excluding) factors, the determination of the factors that enter into the process was the first question to tackle.

\section{A.Multicriteria evaluation}

The Multicriteria Evaluation Method proposed here possesses just one objective, which is none that the land selection to locate grid connected PV power plants, but with certain requirements, that in turn will be determined by the criteria to be described later.
The Multicriteria Evaluation Methods can be divided into three groups:

1. Compensatory techniques.

2. Non-compensatory techniques.

3. Diffuse techniques.

To correctly determine the weight that each criteria or factor has in the final resultant layers output, the Analytical Hierarchies method of [2] within the Multicriteria Evaluation Method has been adopted. It is a pair comparison procedure, that works with a square matrix where the number of columns and rows is defined by the number of criteria to ponder.

The Multicriteria Evaluation Techniques methodology and the Analytical Hierarchies method combined with GIS, have allowed us to check that the values given to each criteria and factor were consistent, based on the achieved Consistency Indexes.

\section{B. Analytical Hierarchies Method}

The fact that the Analytical Hierarchies Method has spread in fields such as fuzzy decision and mathematical programming, is a sign that it is suitable in decision problems in which great fidelity and flexibility are required.

The Analytical Hierarchies Method decomposes a complex problem in hierarchies, where each level is in turn decomposed in specific elements. The main objective is on the first level, and from it, the criteria, sub-criteria and decision alternatives are listed in the descending hierarchy levels.

The eigenvector of the previously mentioned square matrix associated with this problem is computed. This eigenvector provides a quantitative measure of the consistency of the judge of values between pairs of factors.

\section{Data base}

The information from 295 councils in Andalusia has been compiled both related to land and climate properties. This generated a great information volume that had to be managed using the software just mentioned.

The variables that are important to make this data base could be first classified according to the following typologies:

- Social perception of the installation:

o Desirable installations.

o Non-desirable installations.

- Technical conditions:

o Weather data of the area.

o Technology used in the plant.

o Economic data of the inversion.

- Types of lands. 
- Locations.

- Geographic data of the location.

A common feature of the group of models that focus on desirable installations is that they deal and solve a double problem: on one side they determine the optimal location of the equipment and on the other side they assign the demand (users and consumers) to the offer points, of which the definition of service or market areas are derived. For this reason, a quite spread common denomination of them is that of location-assignation models.

It seems logical to think that desirable installations are frequently used (schools, health services, etc.) so that getting to them implies a cost that should be minimised with choosing a correct location.

For non-desirable installations, like dangerous waste management plants, the study objective could focus in minimising negative impacts on the host society, like taking them far from populated areas to avoid the effects. In what respects to the study of this paper, grid connected photovoltaic power plants could be considered 'desirable', since the lack of adverse effects on society and environment during design, development and exploitation. So we could focus on offer and demand factors. Being the generated electric energy the offer, and the demand the society demand for electric energy.

So one of the objectives will be to bring offer and demand closer in what is called 'distributed generation', a factor that will be considered in any location proposal. Regarding weather data, we should consider:

- Global irradiance on horizontal surface.

- Diffuse irradiance

- Direct irradiance.

- Albedo.

- Annual average daily temperatures.

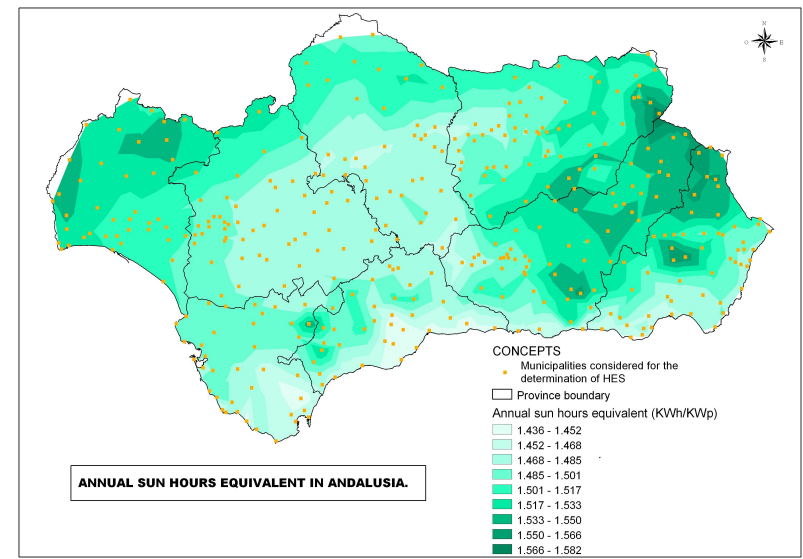

Fig. 1: Annual sun hours equivalent
One of the most influential factor is soil usage, that although it does not influence on production it does represent an environmental variable, so the following parameters should be considered:

- Agricultural value of soil usage.

- Environmental land protection:

o Places of EU interest.

o Places of special bird protection.

o Andalusian Network of Protected Natural Spaces: National Parks, Natural Parks, etc.

o List of Andalusian Wet Lands.

It is important as well to know the location to asses the distances to infrastructures, both to ease communications and to guarantee the generated energy evacuation. So, the following parameters should be considered:

- Distance to populated areas.

- Distance to roads.

- Distance to power lines.

- Distance to substations.

Regarding geographical data:

- Latitude

- Longitude

- Altitude

- Land orography.

\section{Output model}

The final output model (figure 2) is the result of a summation process of the factors, criteria and limiters, via the Arithmetic Overlay methodology. This output model is then normalised and later reclassified, to achieve the final layer. To validate the model, a sensibility and uncertainty analysis is carried out.

The sensibility analysis carried out here consist in modifying the model specifications and check the results variations. So four different models were built changing the different weights both to the criteria and to the input factors and considering in each case different priorities as we will later see.

The starting point model establishes the priority on the Photovoltaic Plant efficiency, that is, more weight are assigned to weather factors and criteria than to any other factor or criteria. This model has been compared with other three different models.

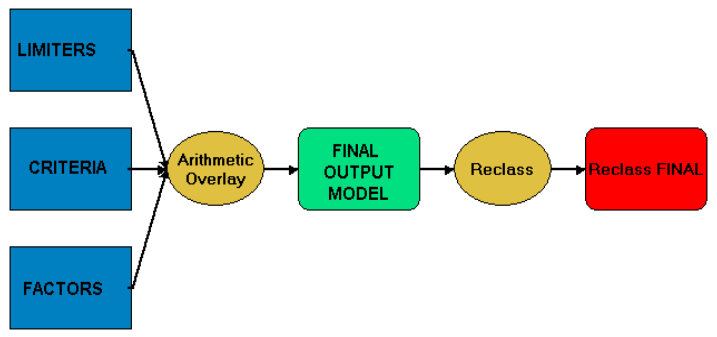

Fig. 2: Final result achievement process 
On the other hand, the uncertainty analysis tries to determine the uncertainty of the independent variables estimations [3].

\section{Particular example}

Figure 3 shows the final result layer of a certain region in the North of the Granada Province. A quite considerable extension reached 7, 8 and 9 points, so it means that there are plenty of suitable spots to build grid connected photovoltaic power plants. This is mainly because the studied area enjoys many sun hours all year round, quite moderate annual mean temperatures and quite high irradiance on horizontal surfaces [4].

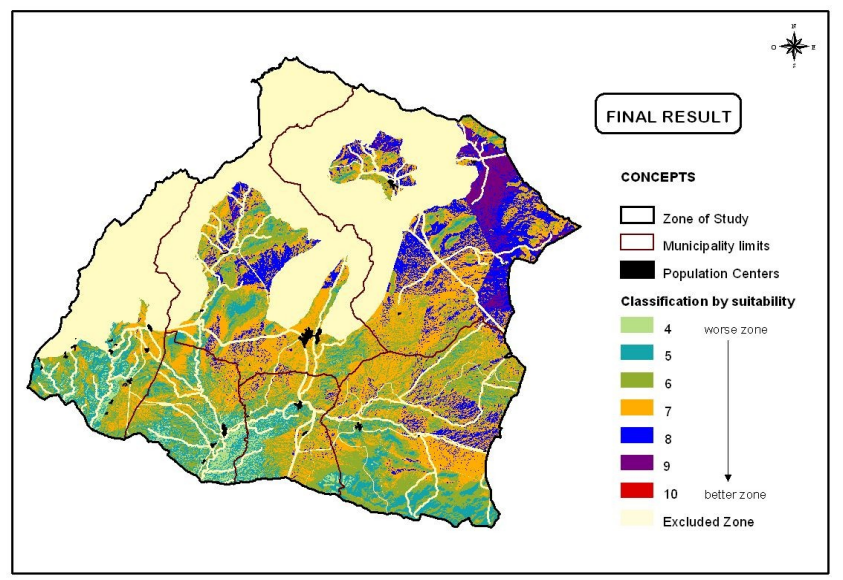

Fig. 3: Final result layer of proposed example

\section{Conclusions}

The obtained spatial decision model is the result of crossing information from a series of layers regarding weather, environmental, orographic and location, as well as limiting or excluding ones (e.g. Natural Park), where a decision methodology (Multicriteria Evaluation and Analytical Hierarchy) has been followed that analyses the weight assigned to each involved factor.

This model can provide us with very valuable information when trying to select appropriate areas to build photovoltaic power plants, with efficiency as the prime objective (because factors as crucial as daily temperature, hours of sun equivalent or sun irradiance levels are considered), but at the same time showing great respect with the environment selecting lands where impact is negligible (on soil and visual).

Furthermore, the model chooses the location considering best road access and proximity to power substations.

To test the model, it has gone through a validation process consisting in three distinct phases, but complementary at the same time:

1. Verification.

2. Validation.

3. Sensibility analysis.
The validation process showed the following. The verification phase consisted in testing that the results fulfil with the input requests, or in other words, that the defined model has been correctly built. For the validation phase pixel by pixel, eye and on site checks have been done, concluding that model and real scenario correspond correctly.

The uncertainty analysis showed that the proposed model has more similarities with the environment-oriented model, than with the other two other variant models (orography oriented and location oriented). So, the proposed model is more stable and thus will have less uncertainty than the other two models. That is, uncertainty is bigger for those models focused on orography and location than for those models focused on environment and weather.

The sensibility analysis (that studies how output changes when input data or methodology are modified) showed similar results: the most important criteria are those related to weather and environment, while the most important factors are weather factor (temperature, irradiance, hours of sun equivalent, etc.). On the other hand, factors like distance to populated areas and road do not influence the result much, so if the model were to be simplified, they could be removed.

\section{References}

[1] JANKOWSKI, P. "Integrating geographical information system and multiple criteria decision-making methods", International Journal of Geographical Information Systems,9(3),pp.251-273.1995.

[2] SAATY,T. A Scaling method for priorities in hierarchical structures, Journal of Mathematical Psychology, $\mathrm{N}^{\circ} 15$ pags. 234-281. 1997.

[3] GÓMEZ DELGADO, M. et al: "Aplicación de análisis de incertidumbre como método de validación y control del riesgo en la toma de decisiones", GeoFocus (Artículos), no 4, p. 179-208. ISSN: 1578-5157.2004.

[4] J. ARÁN CARRIÓN, A. ESPIN ESTRELLA, F. AZNAR DOLS M. ZAMORANO TORO, M. RODRIGUEZ and A. RAMOS RIDAO, Environmental decision-support systems for evaluating the carrying capacity of land areas: Optimal site selection for gridconnected photovoltaic power plants, Renewable and Sustainable Energy Reviews, 6 August 2007. 